\title{
ОСОБЕННОСТИ ОБРАБОТКИ ДАННЫХ ШАХТНОЙ СЕЙСМОРАЗВЕДКИ С ЦЕЛЬЮ РАЗДЕЛЕНИЯ Р И ऽ ВОЛН
}

\author{
А.Г. Ярославцев ${ }^{1}$, И.М. Клестов ${ }^{2}$ \\ ${ }^{1}$ Горный институт УрО РАН, г. Пермь \\ ${ }^{2}$ ПАО «Пермнефтегеофизика», г.Пермь
}

\begin{abstract}
Аннотация: Рассмотрены особенности графа цифровой обработки данных шахтной сейсморазведки, выполняемой на руднике Верхнекамского месторождения солей. Показано, что при обработке $\mathrm{P}$ и $\mathrm{S}$ волн, зарегистрированных в рамках единой полевой технологии, определяющую роль играют процедуры пространственно-временной фильтрации и преобразования Радона.

Ключевые слова: шахтная сейсморазведка, цифровая обработка данных, отраженные волны, поперечные волны, продольные волны.
\end{abstract}

Реализация сейсморазведочных наблюдений в горных выработках Верхнекамского месторождения солей является весьма специфической задачей. В первую очередь это связано с тем, что окружающее выработку пространство осложнено отражающими объектами, которые могут находиться не только в нижнем полупространстве, что характерно для наземной сейсмики, а практически в любом лучевом направлении.

В наиболее оптимальном варианте, который отражен в «Инструкции по шахтной сейсморазведке...» [5], направление возбуждения колебаний должно быть согласовано с желаемым направлением изучения среды. Это позволяет добиться максимальной энергии отраженных сигналов в целевом направлении и снизить пространственную неопределенность при локализации аномалий в водозащитной толще (ВЗТ).

Как показывает практика шахтных сейсморазведочных работ $[3,4,7]$, в соляных выработках из-за практического отсутствия рыхлого влагосодержащего поверхностного слоя энергия S-волн на первичных записях сравнима или превосходит энергию Р-волн. В тоже время в соляных породах волны разных типов не только значимо различаются по скоростям распространения колебаний ( $\mathrm{Vs} / \mathrm{Vp} \approx 0.6)$, но и могут существенно отличаться по спектральным характеристикам. Эти различия лежат в основе технологий шахтной многоволновой сейсмоакустики $[1,2,3]$, используемой с целью выделения аномалий физико-механических свойств ВЗТ.

Рассмотрим приемы цифровой обработки с разделением волновых полей на продольную и поперечную составляющие на примере данных, полученных при изучении целика между двумя рудниками (рис. 1а). Технологически данные получены двумя способами. В первом случае (рис. 1б) возбуждение колебаний производилось в стенку выработки. Это же направление имела ось чувствительности сейсмоприемников, закрепленных возле пунктов возбуждения на стенке выработки. Во втором (рис. 1в) удары производились в кровлю выработки, а вертикальные сейсмоприемники крепились на почве выработки.

При первом способе наблюдений наибольшей интенсивностью (рис. 2а) в сейсмических записях характеризуются отраженные поперечные волны горизонтальной поляризации $(S H)$. Однако они не имеют узкой направленности излучения, поскольку для поперечных волн подобной поляризации диаграмма направленности обладает круговой симметрией относительно направления удара. Следовательно, в единой пространственно-временной области равнозначными амплитудами будут характеризоваться $S H$ волны, отражённые и сверху, и снизу [6]. Разделить такие отражения практически невозможно, поэтому при просвечивании бокового полупространства на отраженных волнах поперечные волны, пришедшие из вертикальной плоскости, будут относиться к помехам. Их подавление является приоритетной задачей при обработке. 


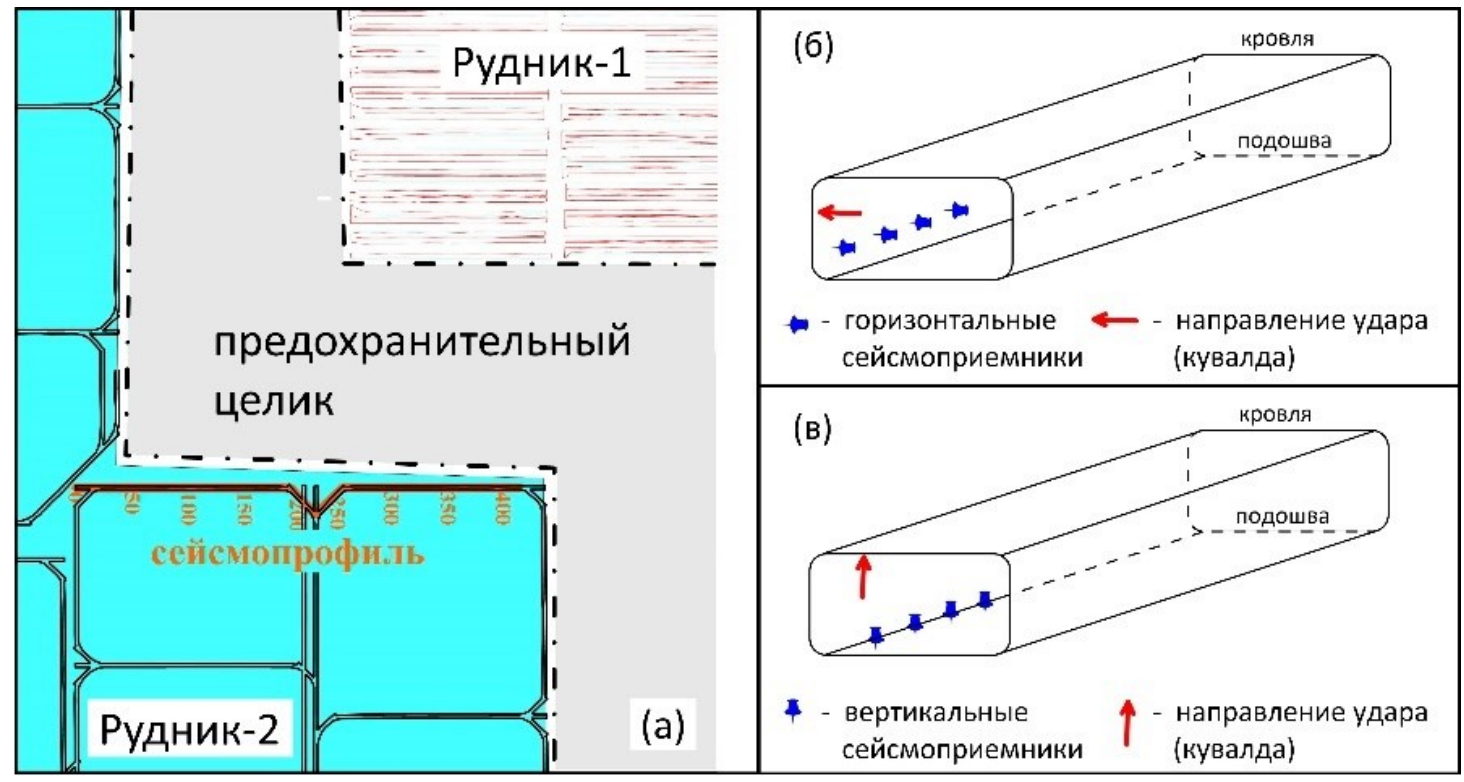

Рис. 1. Расположение сейсмического профиля на схеме выработок (a), схема наблюдений при изучении бокового полупространства (б), схема наблюдений при изучении верхнего полупространства (в)
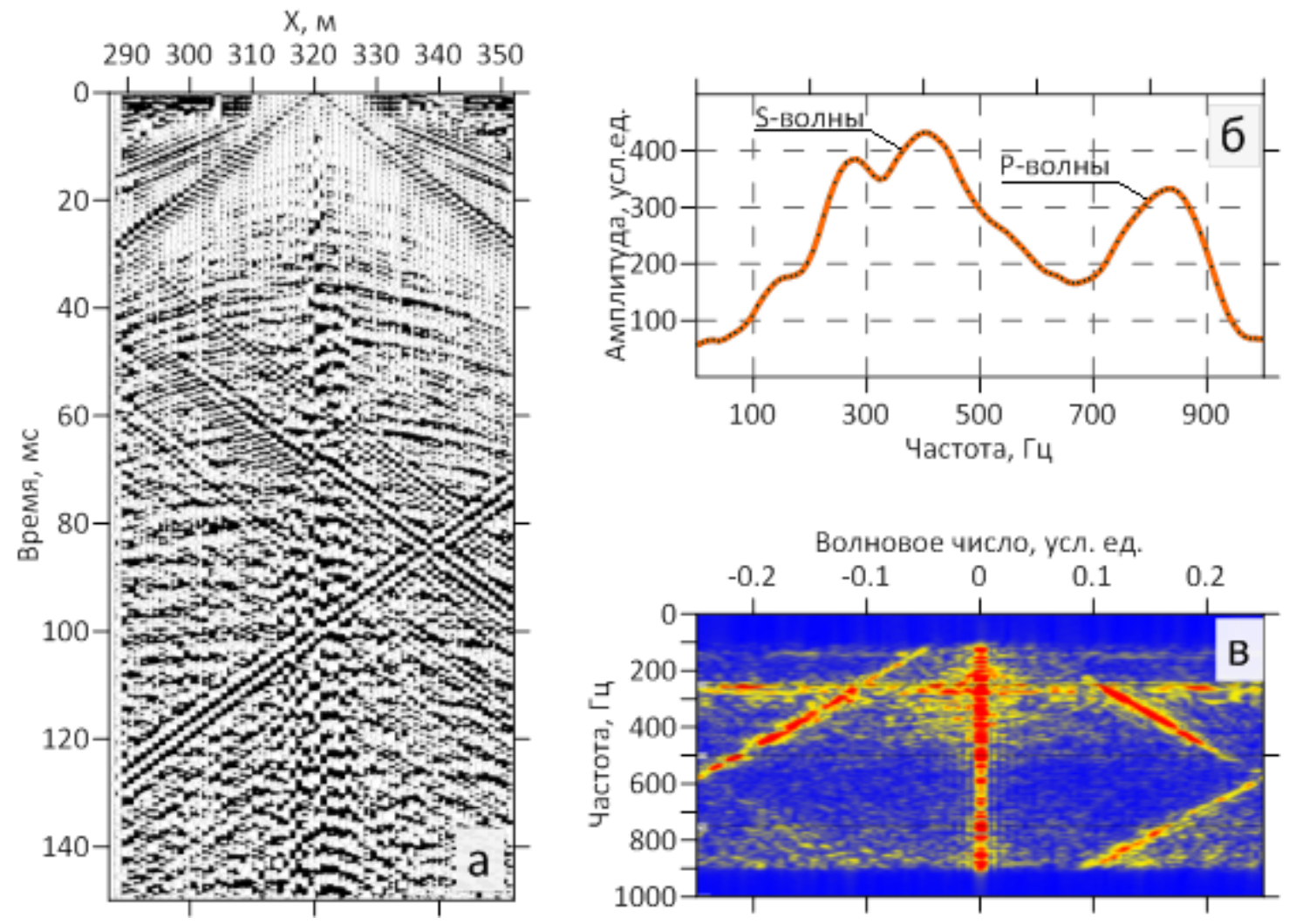

Рис. 2. Данные просвечивания в боковое полупространство:

а) первичная сейсмограмма, ее амплитудный (б) и f-k (в) спектры

Анализ полезной части записи показывает, что при ударах в стенку выработки поперечные и продольные волны уверенно разделяются в амплитудном спектре (рис. 2б). Частотный диапазон Р-волн почти в 2 раза превышает полосу регистрации волн $\mathrm{SH}$. Как показывает практика, это соотношение может меняться в зависимости от пород, по которым пройдена выработка. 
Традиционные для шахтной сейсмики когерентные линейные помехи, являющиеся результатом отражений прямой волны от сбоек выработок, уверенно контролируются в $\mathrm{f}-\mathrm{k}$ области. В нашем случае (рис. 2в), они локализованы в частотной полосе шириной около 40-50 Гц и имеют наклон 80-90 мс на 100 трасс.

На рис. 3 представлены результаты поэтапной фильтрации волновых полей до получения временного разреза, характеризующего горизонтальную плоскость. Для наглядности трассы равных удалений просуммированы на базе 32 сейсмограмм и показаны скоростные спектры.

По сути граф обработки сложно назвать углубленным, т.к. значительное снижение присутствия поперечных волн достигается уже после полосовой фильтрации 500900 Гц (рис. 3в). Полосовая фильтрация позволила в достаточной мере подавить поперечные волны и подготовить данные к контролируемой пространственно-временной фильтрации. На следующем этапе, кроме применения линейного $\mathrm{f}-\mathrm{k}$ фильтра, сконструированного в интерактивном режиме для борьбы с линейными наклонными помехами, улучшение когерентности Р-волн достигается за счет применения пространственно-временной фильтрации с заданными параметрами оператора (рис. Зг). Возможность такой специальной фильтрации реализована в процедуре RECON из пакета программ SPS-PC (ООО «Калуднет», Россия) и подразумевает подавление всех осей синфазности с кинематикой отличной от полезных волн. После данного набора процедур максимумы коэффициентов когерентности на развёртке скоростей оказываются достаточно четко локализованными в районе $3800-4400$ м/с (рис. 3д). Т.е. можно считать, что помехи (S-волны) подавлены практически полностью.

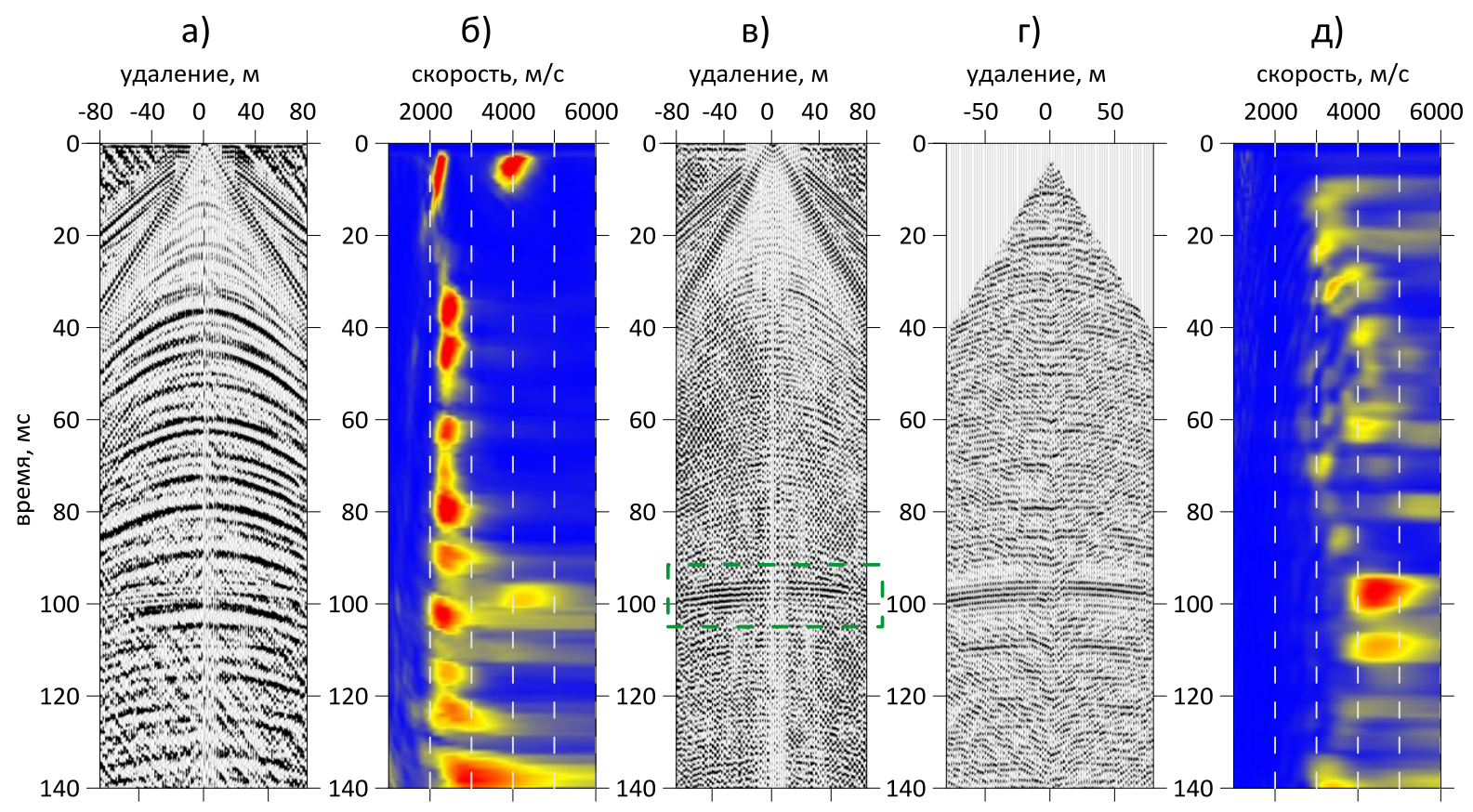

Рис. 3. Этапы обработки Р-волн при просвечивании в боковое полупространство:

a) f-k фильтрация наклонных прямолинейных волн помех, полосовая фильтрация 100-900 Гц, амплитудная регулировка, б) спектр скоростей до подавления $\mathrm{S}$ волн, в) полосовой фильтр 500-1000 Гц, в) мьютинг, пространственно-временная фильтрация недоспрямленных волн SH (Recon), деконволюция; г) уточнение скоростного закона Р-волн по спектрам Semblance

На завершающем этапе обработки выполнена 45-градусная конечно-разностная миграция по временному разрезу, который для наглядности трансформирован в глубинный домен (рис. 4а) с постоянной скоростью 4300 м/с. В итоговом волновом поле с пк. 
265 и до конца профиля на удалении порядка 200 м уверено выделятся группа осей синфазности, сформированных на границе целика и отработанного массива (затопленный рудник). Внутри целика наблюдаются менее интенсивные отражения, по их поведению при дальнейшей интерпретации предполагается их структурно-литологическая неоднородность.

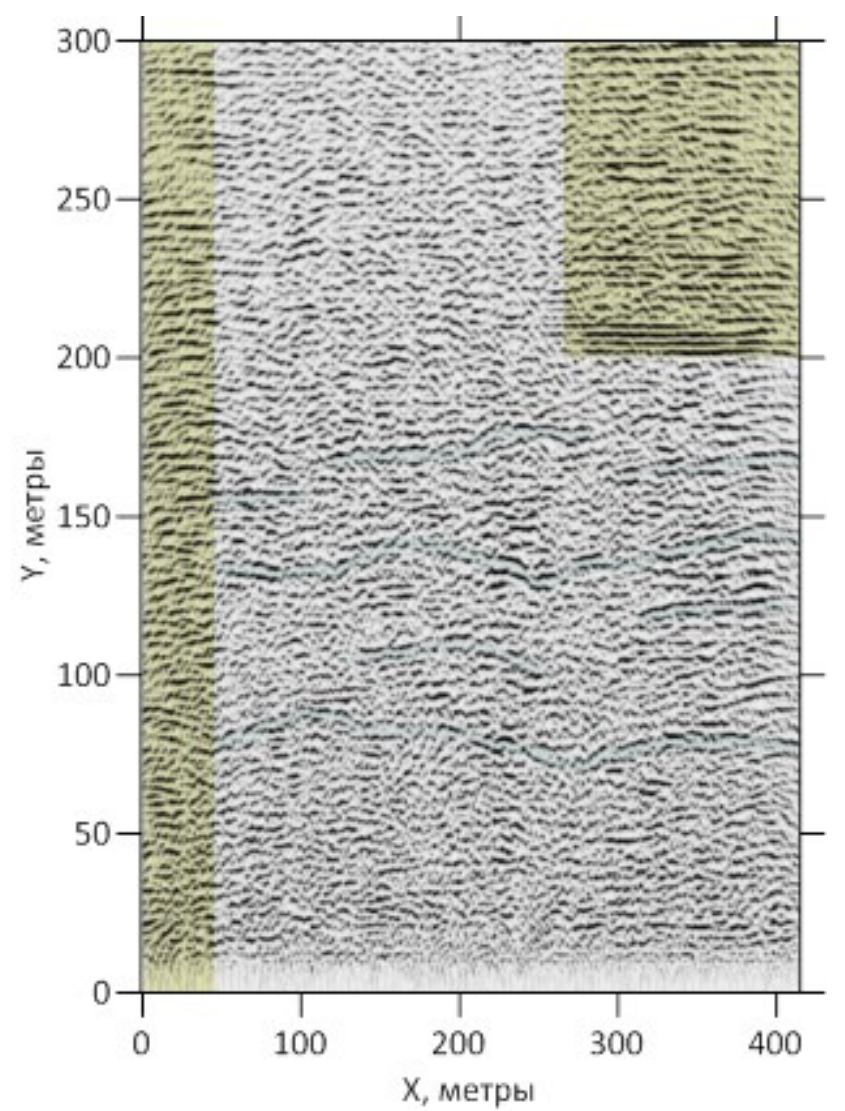

Рис. 4. Итоговый сейсмический разрез Р-волн (боковое полупространство) после процедуры миграции

При изучении разреза в вертикальном направлении (генерация волн в верхнее полупространство) разделение волнового поля на продольную и поперечную (SVволны) составляющие оказывается несколько сложнее. По интенсивности Р-волны близки к $\mathrm{S}$ только на ближних удалениях (рис. 5), а их преобладающие частоты различаются незначительно. Кроме того, волны обоих типов могут быть полезными для интерпретации.

Следуя упрощенном графу обработки, схожему с обработкой просвечивания, удается в достаточной мере разделить волновое поле на $\mathrm{P}$ и $\mathrm{S}$ составляющие. Так, после применения процедуры RECON в результатах скоростного анализа (рис. 6) достаточно отчетливо проявляется зависимость, характерная для отраженных Р-волн.

Применение углубленной обработки этих же материалов в пакете программ «Geocluster» версии 5000 («CGG», Франция) позволяет получить кондиционные временные разрезы и для Р и для SV-волн.

Из особенностей углубленной обработки следует отметить, что все процедуры подавления линейных и случайных волн помех, а также коррекция статических поправок выполнялись с опорой на наиболее интенсивные S-волны.

Последующее разделение волнового поля на продольную и поперечную составляющие выполнено процедурой высокоразрешенного преобразования Радона по сейсмограммам ОГТ непосредственно перед применением временной миграции Кирхгофа. 


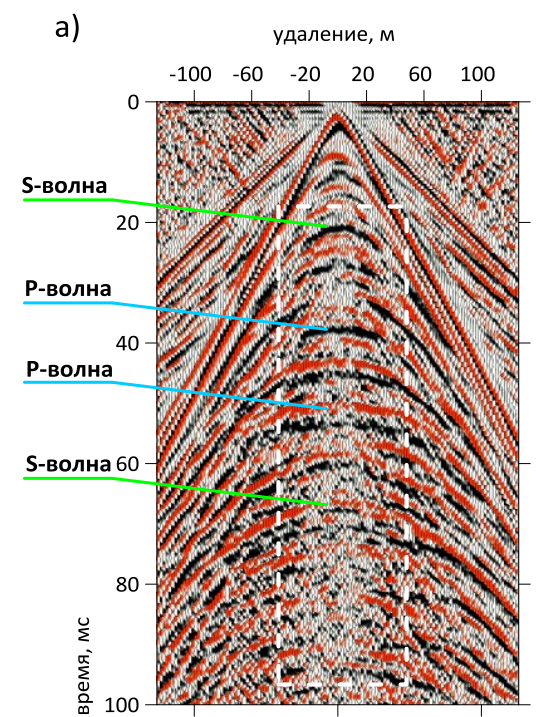

б)

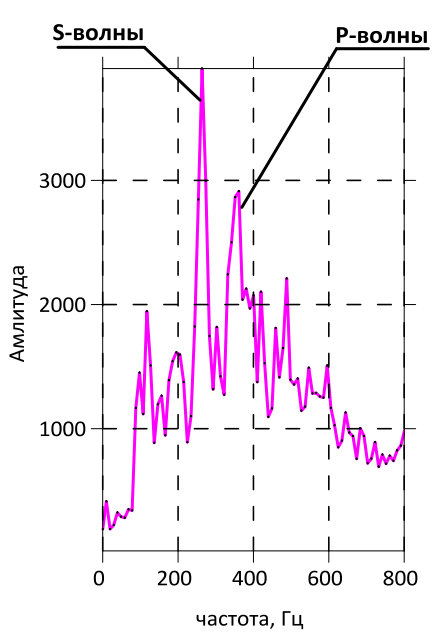

Рис. 5. Наблюдения в верхнее полупространство:

а) первичная суперсейсмограмма (пунктиром область спектрального анализа), б) амплитудный спектр

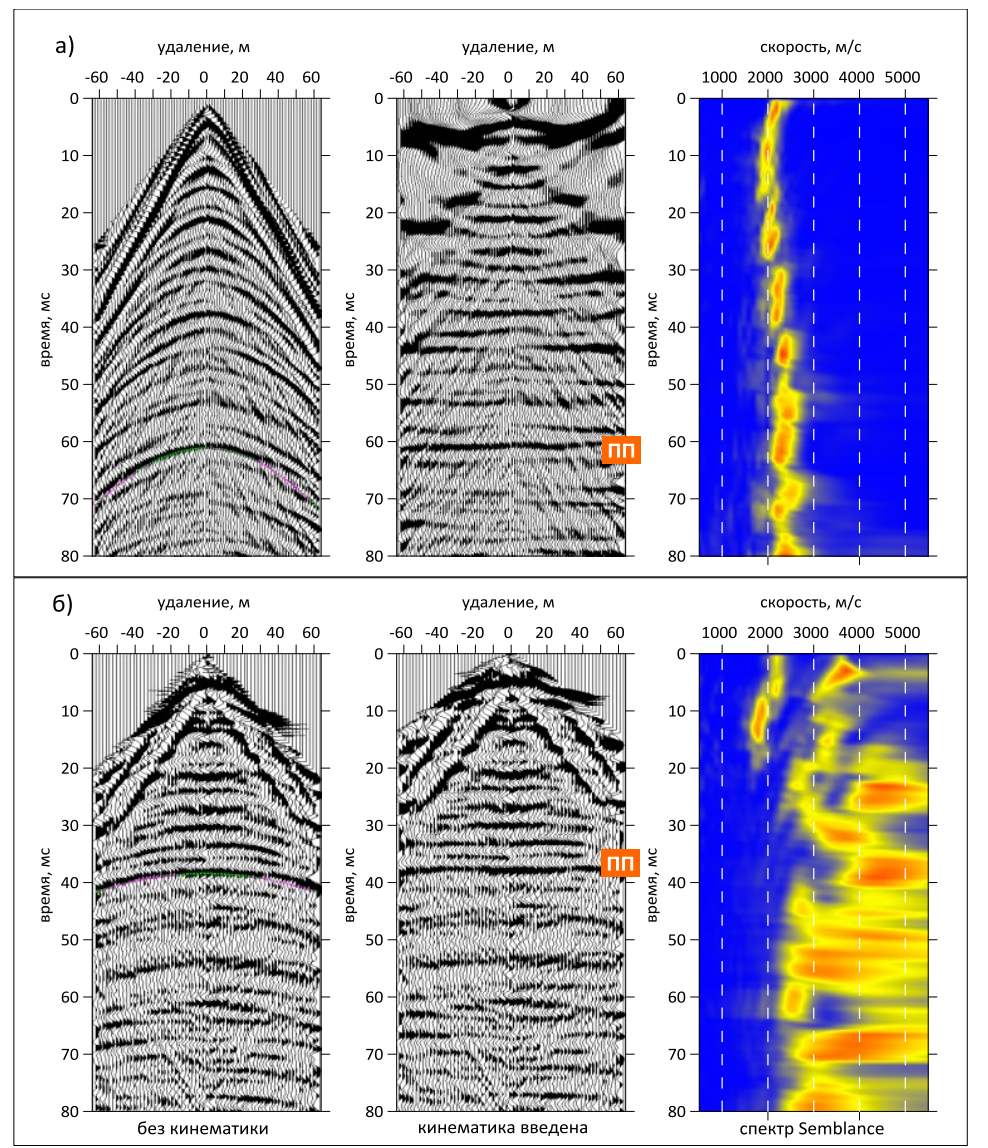

Рис. 6. Результаты скоростного анализа по суперсейсмограмме (ПК $300-350)$ после применения процедур подавления Р-волн (а) и S-волн (б)

Окончательные результаты постпроцессинга приведены на рис. 7. На обоих разрезах достаточно четко проявляется слоистая структура соляной толщи. Разрез Р-волн представляется более динамически выраженным с четкой локализацией кровли солей. В тоже время волновое поле поперечных (SV) волн имеет большую вертикальную разрешенность и оказывается менее чувствительным к искривлению профиля на ПК200-250. 

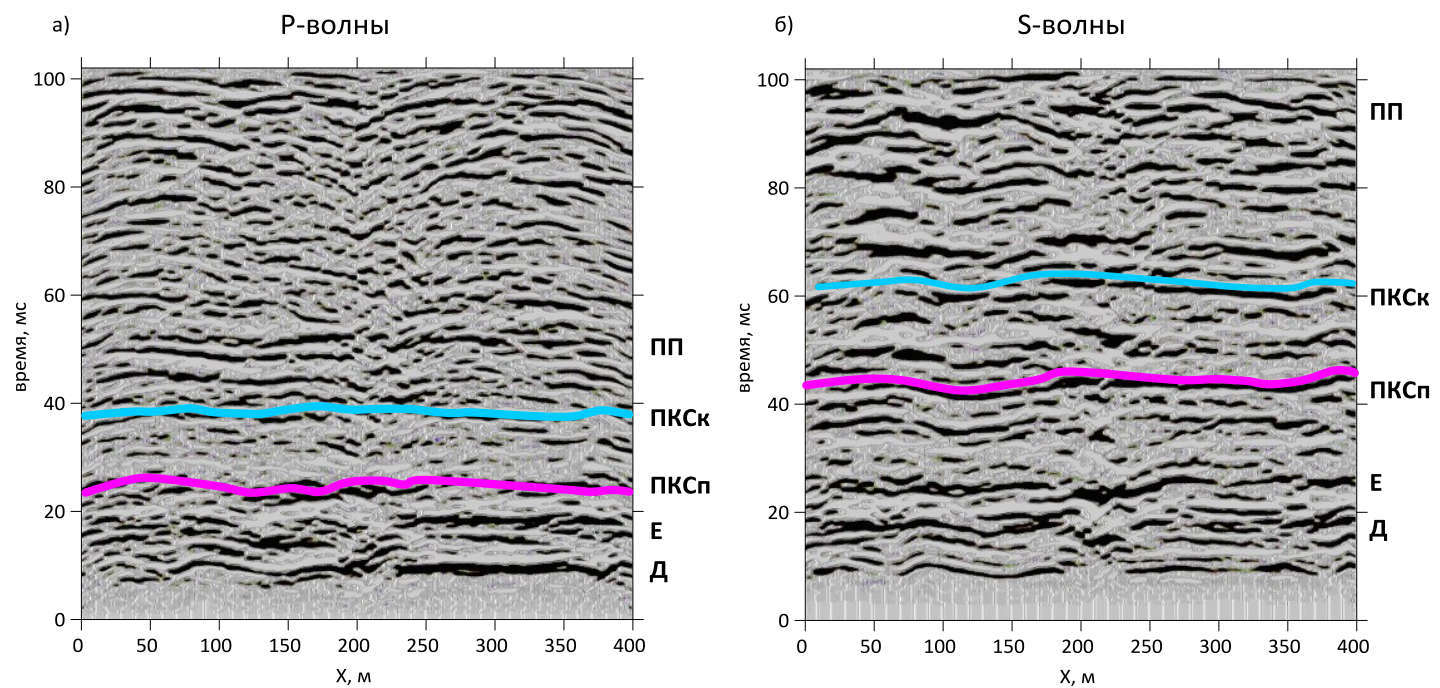

Рис. 7. Результаты углубленной обработки данных шахтной сейсморазведки, зарегистрированных в рамках единой технологии: а) временной разрез ОГТ для Р-волн,

б) временной разрез ОГТ для S-волн

В итоге можно заключить, что успешное разделение волновых полей возможно за счет использования как пространственно-временных фильтров, так и за счет методик преобразования Радона.Наиболее распространенным является применение параболического преобразования Радона с целью подавления отраженных волн с нецелевой кинематикой. Преобразование гиперболических осей синфазности в параболы перед прямым преобразованием Радона осуществляется одним из двух способов: 1) ввод кинематических поправок в соответствии со скоростями суммирования Vnmo, 2) «растяжение» трассы преобразованием оси времен t0 в ось квадратов времен t02. Предпочтительным является второй способ, т. к. не искажает сигнал и превращает гиперболу в точную параболу. Однако он требует большего диапазона кинематических поправок в преобразовании Радона.

Исследование выполнено при финансовой поддержке Программы ФНИ, проект № 0422-2019-0146-С-02 (регистрачионный номер темь НИОКТР: AAAA-A18-118040690028-5)

\section{БИБЛИОГРАФИЧЕСКИЙ СПИСОК}

1. Бабкин, А.И., Санфиров, И.А. Практические примеры решения горнотехнических задач методами шахтной сейсмоакустики // Горный информационно-аналитический бюллетень (научно-технический журнал). - 2011 - № 4. - С.152-159.

2. Бабкин А.И., Санфиров И.А. Сейсморазведочный прогноз литологических неоднородностей в горизонтальной плоскости межштрекового пространства // Горный информационно-аналитический бюллетень (научно-технический журнал). - 2011. - № 11. - С. 55-60.

3. Бабкин А.И. Шахтная сейсмоакустика по методике многократных перекрытий (на примере Верхнекамского месторождения калийных солей): автореф. дис. ... канд. техн. наук: 25.00.16: защищена 21.11.01 / Бабкин Андрей Иванович. - Пермь, 2001. - 20 с.

4. Вагин В.Б. Шахтные сейсмические методы изучения строения массивов соляных пород. - Минск: БелНИЦ «Экология», 2010. - 186 с.: ил.

5. Инструкция по шахтной сейсморазведке (применительно к условиям Верхнекамского месторождения калийных солей): утв. ГИ УрО РАН, ПАО "Уралкалий" / ГИ УрО РАН; Санфиров И.А., Бабкин А.И. - Пермь, 2014. - 37 с.

6. Санфиров И. А., Бабкин А. И., Ярославцев А. Г. О перспективах изучения поперечных волн в горных выработках соляных рудников // Горный информационно-аналитический бюллетень (научнотехнический журнал). - 2020. - № 7. - C. 45-63. - DOI: 10.25018/0236-1493-2020-7-0-45-63.

7. Gendzwill D.J., Brehm R. High-resolution seismic reflections in a potash mine // Geophysics. - 1993. - V. 58, № 5. - P. 741-748. DOI: 10.1190/1.1443459. 